\title{
Epidural Analgesia for Management of Labour Pain: Determinants and Deterrents Among Obstetricians in Nigeria
}

\author{
Okechukwu B. Anozie ${ }^{1^{\star} \mathbb{D}}$, Lucky O. Lawani $^{1}$, Johnbosco E. Mamah ${ }^{1}$, Chidi. O. Esike ${ }^{1,4}$, Olisaemeka P. \\ Ezeonu ${ }^{1}$, Justus N. Eze ${ }^{2}$, Robinson C. Onoh ${ }^{1}$, Onwe E. O. ${ }^{3}$, O. R. Anozie ${ }^{4,5}$, Richard L. Ewah ${ }^{5}$
}

\begin{abstract}
Objectives: The aim of this study was to assess the utilization of epidural analgesia, its determinants and deterrents among Obstetricians.

Materials and Methods: A questionnaire-based cross-sectional study was conducted among obstetricians who attended the Annual Scientific Conference of the Society of Gynecology and Obstetrics of Nigeria in 2016. A total of 324 questionnaires were analyzed using Epi-info statistical software.

Results: Knowledge of epidural analgesia was high (100\%), while availability was $77.8 \%$, however only about $25.9 \%$ routinely prescribed it. The majority $(96.2 \%)$ of the respondents practiced in tertiary health facilities in urban locations (94.1\%). Almost three quarter $(237 / 324 ; 73.1 \%)$ of respondents were males while $87(26.9 \%)$ were females. Female obstetricians were more likely to prescribe epidural analgesia for pain management in labor $(68.9 \%$ vs $63.3 \%, \mathrm{P}$ value $=0.001)$. The greatest impediment to its use was the cost (69.4\%), lack of skill (27.8\%), client's refusal (13.9\%) and fear of complications (10.2\%). Over 95\% of obstetricians whose patients had used epidural analgesia expressed satisfaction and good fetomaternal outcome of labor.

Conclusions: There is a huge disparity between knowledge of epidural analgesia and actual practice among obstetrician. In closing this gap, obstetricians must do more to adequately educate patients on the options of pain relief and routinely offer it for a satisfying birth experience.

Keywords: Labor, Analgesia, Epidural, Practice, Obstetricians, Nigeria
\end{abstract}

\section{Introduction}

Pain perception in labor is extremely variable among women depending on the parturient pain threshold and reaction to pain (1). For the majority of women, labor pain is considered severe and may be likened in severity to complex regional pain syndrome or amputation of a digit without anaesthesia (2). According to the American College of Obstetricians and Gynecologists and the American Society of Anaesthesiologists, there is no circumstance where it is acceptable for an individual to experience untreated severe pain, amenable to safe intervention, while under the care of a physician (2). The development of modern analgesia and in particular regional analgesia marked a major turning point in pain management during labor and delivery. Epidural analgesia is considered as the most effective method of pain relief and recommended as the first choice analgesia for women during labor and delivery $(3,4)$.

The level of awareness and practice of labor analgesia, particularly epidural analgesia in sub-Saharan Africa is still rudimentary and obstetricians undoubtedly have an important role to play in this regard. In 2012, a survey of the practice of labor analgesia a m ong the obstetricians in Nigeria revealed that only $49 \%$ of the respondents offered analgesia to women in labor and of these, a paltry $2 \%$ used epidural analgesia (5).

Pain management in labor is an important component of active management of labor and even though not all women request pain relief in labor, the obstetrician has a duty to discuss the options, benefits and risks associated with various methods of labor analgesia with the parturient irrespective of his or her belief (6, $7)$. Optimal pain control in labor is more likely to result in a satisfactory birth experience for the parturient and her care provider (8-12). A critical step in achieving this milestone is to survey the level of awareness of epidural analgesia, determinants and deterrents of its use among obstetricians practicing in Nigeria.

Currently, there is no available literature documenting the utilization pattern, determinants and deterrents of epidural analgesia among obstetric care providers such as obstetricians in Nigeria. This study, therefore,

Received 8 December 2017, Accepted 27 July 2018, Available online 18 August 2018

${ }^{1}$ Department of Obstetrics and Gynecology, Federal Teaching Hospital Abakaliki, Ebonyi State, Nigeria. ${ }^{2}$ Department of Obstetrics and Gynecology, Ebonyi State University Abakaliki, Ebonyi State, Nigeria. ${ }^{3}$ Department of Paediatrics, Federal Teaching Hospital, Abakaliki, Nigeria. ${ }^{4}$ Department of Radiology, Federal Teaching Hospital, Abakaliki, Ebonyi State, Nigeria. ${ }^{5}$ Department of Anasthesia, Federal Teaching Hospital, Abakaliki, Ebonyi State, Nigeria

*Corresponding Author: Okechukwu B. Anozie, Tel: +234 8035497498, Email: okeyanoziey2k@yahoo.com 
aimed to assess the knowledge of Nigerian obstetricians regarding epidural analgesia, determine the frequency of its use in their practice, enquire about barriers and facilitators of uptake by parturient and evaluate the fetomaternal outcome/experience from the perspective of obstetricians in Nigeria. The findings will be used in making recommendations on how to overcome gaps and improve the health of women and their satisfaction with the process of childbirth. Moreover, it will provide nonexistent local literature and data on the subject matter.

\section{Materials and Methods}

A questionnaire-based cross-sectional study was conducted among Nigerian obstetricians who attended the annual general meeting and scientific conference of the Society of Gynaecology and Obstetrics of Nigeria (SOGON); the umbrella body to which registered obstetricians and gynaecologists in Nigeria belong. SOGON was established in 1965 to regulate obstetrics and gynecological practice in Nigeria. This annual event is usually well attended and features scientific presentations and discussions on issues that deal with women's health. The 50th annual meeting held in 2016 in Akure, Ondo State, Southwest Nigeria provided an ideal avenue for the study of this subject.

Self-administered questionnaire was used for data collection. Prior to this, the questionnaire was pretested on 40 randomly selected doctors who did not participate in the conference and it was thereafter corrected and modified for clarity. A total of 350 questionnaires were administered to obstetricians and gynecologists who consented to participate in the study, but only 324 questionnaires were correctly filled and returned.

Twenty-six questionnaires were either not returned or incorrectly filled, which were excluded from the study. The questionnaire assessed the socio-demographic characteristics, duration of practice, the location of practice, knowledge of determinants and deterrents of the practice of epidural analgesia, as well as provider's assessment of patients' satisfaction with their birthing experience with or without epidural analgesia.

Data were collated and analyzed with Epi Info statistical software version 7.0 (Center for Disease Control and Prevention, USA), and conclusions were drawn by means of descriptive statistics.

\section{Results}

A total of 324 questionnaires out of 350 were eligible for analysis; representing a response rate of $92.6 \%$. Table 1 depicts the socio-demographic characteristics of the respondents with over four-fifths of the respondents within the age range of $40-50$ years $(86.1 \%)$. Almost three quarter were males $(73.1 \%)$ and a little more than onefifth were females (26.9\%). Interestingly, $40.7 \%$ of the respondents had practiced for more than 6 years while $36.1 \%$ and $23.2 \%$ had practiced for $4-6$ years and $1-3$ years respectively.
More than $90 \%$ of the respondents practiced in urban locations, while only $6.5 \%$ were in rural locations. Similarly, about $80.6 \%$ of the respondents practiced in tertiary health institutions, $13.9 \%$ in the secondary centers, while $5.6 \%$ were in private practice (Table 1 ).

Table 2 shows the knowledge of epidural analgesia among respondents. All the respondents knew that

Table 1. Socio-demographic Characteristics, $\mathrm{N}=324$

\begin{tabular}{lc}
\hline Variables & No. (\%) \\
\hline Age (y) & $3(0.90)$ \\
$20-30$ & $135(41.7)$ \\
$31-40$ & $144(44.4)$ \\
$41-50$ & $39(12.0)$ \\
$51-60$ & $3(0.9)$ \\
$>60$ & \\
Sex & $237(73.2)$ \\
Male & $87(26.9)$ \\
Female & \\
Duration of practice $(\mathrm{y})$ & $75(23.2)$ \\
$1-3$ & $117(36.1)$ \\
$4-6$ & $132(40.7)$ \\
$>6$ & \\
Place of practice & $21(6.5)$ \\
Rural & $303(93.5)$ \\
Urban & \\
Institution of practice & $261(80.6)$ \\
Tertiary & $45(13.9)$ \\
Secondary & \\
Private & \\
\hline & \\
\hline
\end{tabular}

Table 2. Knowledge of Epidural Analgesia (EA), $N=324$

\begin{tabular}{lcc}
\hline Variable & No. & $\%$ \\
\hline EA is a form of obstetric analgesia & 324 & 100 \\
Yes & 0 & 0.00 \\
No & 0 & 0.00 \\
Don't know & & \\
EA is the most effective obstetric analgesia & 318 & 98.2 \\
Yes & 3 & 0.9 \\
No & 3 & 0.9 \\
Not sure & 12 & 3.7 \\
EA is administered by & 309 & 95.4 \\
Obstetrician & 3 & 0.9 \\
Anesthetist & & \\
Any health worker & 303 & 93.5 \\
Who should benefit from EA & & \\
All women who consent & 24 & 7.4 \\
High risk parturient & 56 & 15.7 \\
Those who can afford it & & \\
Training on EA & 51 & 79.6 \\
Yes & & 20.4 \\
No & & \\
\hline
\end{tabular}

${ }^{\text {a Multiple options }}$ 
epidural analgesia was a form of labor analgesia but 98.2\% of them knew it was the most effective labor analgesia. An overwhelming majority of respondents (93.5\%) believed it should be offered to all women in labor. An impressive number (79.6\%) of the respondents have received one form of training in epidural analgesia but surprisingly only about a quarter (25.9\%) routinely offer it for pain management in labor.

Regarding the level of practice of epidural analgesia as shown in Table 3, a significant $(77.8 \%)$ proportion of the respondents reported the availability of epidural analgesia in their institutions but only a paltry $25.9 \%$ offered it routinely to women in labor, $63.9 \%$ used it occasionally and $10.2 \%$ never used it. Of those whose clients have used epidural analgesia in labor, $94.2 \%$ were satisfied with the level of pain relief experienced by the parturient, while the remainder $(5.8 \%)$ were not.

Table 4 depicts the reasons for non-use. The reasons for non-use were the cost (69.4\%), lack of skill (27.8\%), patients refusal $(13.9 \%)$, fear of complications $(10.2 \%)$ and religious beliefs (2.8\%).

Female obstetricians were more likely to prescribe epidural analgesia $(68.9 \%$ vs $63.3 \%, P$ value $=0.001)$. The practice location and institutional types of respondents who used epidural analgesics in managing parturient in labor are shown in Table 5, indicating that only $28.6 \%$ of the respondents practicing in rural areas had used epidural analgesia and $96.2 \%$ of practitioners in tertiary facilities.

\section{Discussion}

This study showed that despite a high level of knowledge of epidural analgesia among obstetricians practicing in Nigeria, there was a huge gap between the knowledge possessed and the actual practice of routinely offering epidural analgesia to parturient for labor pain management. This is similar to the findings among care providers in Ethiopia where it is believed that pain

Table 3. Practice of Epidural Analgesia (EA) in Labor, $N=324$

\begin{tabular}{lcc}
\hline Variables & No. & $\%$ \\
\hline EA is available in my facility & 294 & 90.7 \\
Yes & 15 & 4.6 \\
No & 15 & 4.6 \\
Not sure & & \\
Frequency of use of EA & 84 & 25.9 \\
Routine & 207 & 63.9 \\
Occasionally & 33 & 10.2 \\
Never & & \\
My experience with use of EA in labor & 274 & 94.2 \\
Satisfied & 33 & 5.8 \\
Not satisfied & & \\
Commonest analgesia used & 290 & $89.5 \%$ \\
Opioids
\end{tabular}

Table 4. Reasons for Non-use of Epidural Analgesia in Labor, $n=33$

\begin{tabular}{lcc}
\hline Impediments $^{\mathbf{a}}$ & No. & $\%$ \\
\hline Lack of skill & 90 & 27.8 \\
Expensive & 225 & 69.4 \\
Against my religion & 9 & 2.8 \\
Against my culture & 3 & 0.9 \\
Fear of complications & 33 & 10.2 \\
Need to allow natural labor & 12 & 3.7 \\
Clients refusal & 45 & 13.9 \\
None & 18 & 5.6 \\
\hline
\end{tabular}

Multiple options.

Table 5. Use of Epidural Analgesia, $\mathrm{N}=291$

\begin{tabular}{ll}
\hline Variable & No. (\%) \\
\hline Based on sex & $150(63.3)$ \\
Male obstetricians & $60(68.9)$ \\
Female obstetricians & \\
Based on duration of practice & $65(86.7)$ \\
$1-3$ & $103(88.0)$ \\
$4-6$ & $123(93.2)$ \\
$>6$ & \\
Based on level of care & $251(96.2)$ \\
Tertiary & $30(66.7)$ \\
Secondary & $10(55.6)$ \\
Private & \\
Based on location of practice & $285(94.1)$ \\
Urban & $6(28.6)$ \\
Rural &
\end{tabular}

relief in labor should not be a priority since labor is a natural process (13), this is however at variance with the reports from high income settings where there were high awareness and use of epidural pain relief in labor $(14,15)$.

Providing pain relief using effective analgesia like epidural is very important, considering that the process of childbirth is a life-changing event and the care which a pregnant woman receives during this important event may have a long-term emotional and psychological impact on her and this by extension may affect the health of the baby (16). This is consistent with the finding by Lim et al who reported that the extent of labor pain relief by epidural analgesia predicts lower postpartum depression scores (17). A parturient in labor should have a satisfying birthing experience that would make her look forward to her next pregnancy with enthusiasm. The role of obstetricians in making this a reality cannot be overemphasized and a pain-free labor is very vital if this is to be achieved (5). It is important that the woman receive enough information about the various options of pain relief and be guided into making an informed choice (18).

It is pertinent to note that the level of knowledge of epidural analgesia among the respondents was high with over $95 \%$ of respondents having accurate knowledge regarding epidural analgesia, its benefits and indications. 
However, about $79.6 \%$ of them had received some forms of specialized training in epidural analgesia, emphasizing the need for more regular updates and competency-based training in this area of the patient management.

Despite current evidence that shows epidural analgesia to be the most effective, most flexible, least depressive of the central nervous system, for an alert mother and fetus/neonate (19), this study indicates that its level of use among obstetricians practicing in Nigeria is a far cry from the optimum standard, with only $25.9 \%$ administering epidural analgesia routinely. However, this is an improvement on the $2 \%$ reported in an earlier study by Lawani et al during a similar conference held 4 years prior to the current study (5). This may have been due to an improvement in the care of women during child birth as currently being advocated by SOGON, with pain relief being a frontline issue in this campaign. Moreover, this finding is higher than the $11 \%$ reported in a Turkish study (7), but far less than the high utilization rate observed in other studies conducted in most high-income countries $(6,20)$.

Interestingly, a greater proportion of female obstetricians compared to their male counterparts in the present study had recommended epidural analgesia for parturient in labor. This might be because women themselves having experienced labor pain may be more inclined to provide pain relief for other women. In addition, more obstetricians with longer duration of practice, those practicing in urban and tertiary centers provided epidural analgesia readily for women in labor than their other counterparts. This may be attributed to practice experience, availability of personnel, materials and equipment for its administration and monitoring, as often seen in tertiary institutions or advanced settings such as in high-income countries where there is a higher level of utilization of epidural analgesia $(6,20)$.

The greatest determinant of its use was cost, while other impediments were lack of skills, clients refusal, fear of complications and religion beliefs. Similar studies have also adduced comparable reason for poor utilization in some other similar settings $(8,13)$. Knox et al identified several contextual factors which facilitated or were barriers to birth without epidural analgesia in tertiary health centers in Canada, with the following themes emerging from differing perceptions of pain, care providers ready for things to go wrong and insufficient resources (17).

These findings once again bring to fore the need for subsidization of the cost of healthcare services which can be done under a comprehensive health insurance scheme. It is also important to train and retrain all cadres of labor ward staff in the skills required for administration and management of epidural analgesia in labor (22).

Leaving such an important tool in the hands of anaesthetists alone that in most case are few and overworked would definitely deprive our patients of the potential benefits of epidural analgesia in labor.
Epidural analgesia is not without complications but with the requisite skill and adequate monitoring, its complications can almost be eliminated. In the present study, $94 \%$ of the study participants were satisfied with fetomaternal outcome following the use of epidural analgesia in labor. This is in tandem with the report by the American College of Gynecologist and Liv et al in the United Kingdom where the utilization of epidural analgesia in labor was associated with good fetomaternal outcomes and greater satisfaction when compared with other methods of intra-partum pain management $(14,24)$.

\section{Conclusions}

In conclusion, the routine prescription and utilization of epidural analgesia by Nigerian obstetrician who is the custodian of women's health is still quite suboptimal, despite the overwhelming high level evidence which has clearly shown that many of fears, unsubstantiated risks, as well as the unfounded myths ascribed to epidural analgesia in labor are baseless and that its benefits far outweigh any risks to both mother and baby $(1,8,24,25)$. Therefore, adequate patient education, training of personnel and subsidization of this service will go a long way in promoting the acceptability and utilization of epidural analgesia for women in labor. Specifically, support could be improved through the implementation of guidelines for assessment and management of labor pain, provision of a variety of pain management options, and labor support training for healthcare professionals (21).

\section{Strength and Limitation}

The major strength of this study was the high response rate from the respondents who were directly involved in the management of parturient in labor, however, one limitation was that it did not include the views of some obstetricians who were registered members of SOGON, but absent from its 2016 Annual General Meeting/ Conference.

\section{Area for Further Research}

An interventional randomized controlled study assessing 2 groups of care providers who had regular update training in epidural analgesia and those without update training, with the aim of assessing the practice of offering epidural analgesia after the period of intervention (training) will help proffer solution to the problems of non-routine labor pain management with epidural analgesia.

\section{Conflict of Interests}

Authors declare that they have no conflict of interests.

\section{Ethical Issues}

Ethical clearance for the study was obtained from the local organizing committee of SOGON 2016. 


\section{Financial Support}

There was no financial support from any organisation or institution.

\section{References}

1. Bilic N, Djakovic I, Klican-Jaic K, Rudman SS, Ivanec Z. Epidural Analgesia in Labor-Controversies. Acta Clin Croat. 2015;54(3):330-336.

2. Hawkins JL. Epidural analgesia for labor and delivery. N Engl J Med. 2010;362(16):1503-1510. doi:10.1056/ NEJMct0909254

3. Duale C, Bonnin M. Local anaesthetic epidural solution for labour: About concentrations and additives. In FynefaceOgan S, ed. Current Views and Approaches. Intech; 2012.

4. Rao ZA, Choudhri A, Naqvi S, Ehsan Ul H. Walking epidural with low dose bupivacaine plus tramadol on normal labour in primipara. J Coll Physicians Surg Pak. 2010;20(5):295-298. doi:05.2010/jcpsp.295298

5. Lawani LO, Eze JN, Anozie OB, Iyoke CA, Ekem NN. Obstetric analgesia for vaginal birth in contemporary obstetrics: a survey of the practice of obstetricians in Nigeria. BMC Pregnancy Childbirth. 2014;14:140. doi:10.1186/1471-2393-14-140

6. Klein MC, Grzybowski S, Harris S, et al. Epidural analgesia use as a marker for physician approach to birth: implications for maternal and newborn outcomes. Birth. 2001;28(4):243-248.

7. Pirbudak L, Balat O, Kutlar I, Ugur MG, Sarimehmetoglu F, Oner U. Epidural analgesia in labor: Turkish obstetricians' attitudes and knowledge. Agri. 2006;18(2):41-46.

8. Iliyasu Z, Galadanci HS, Abubakar IS, Isah H, Aliyu MH. Desire for obstetric analgesia among women in northern Nigeria. Trop J Obstet Gynaecol. 2012;29(2):53-61.

9. Hitzeman N, Chin S. Epidural analgesia for labor pain. Am Fam Physician. 2012;86(3):241-242.

10. McGrady E, Litchfield K. Epidural analgesia in labour. Continuing Education in Anaesthesia Critical Care \& Pain. 2004;4(4):114-117. doi:10.1093/bjaceaccp/mkh030

11. King Edward Memorial hospital. Epidural analgesia in labour. Clinical guidelines, medical section E. 2014;1-7.

12. Freeman LM, Bloemenkamp KW, Franssen MT, et al. Remifentanil patient controlled analgesia versus epidural analgesia in labour. A multicentre randomized controlled trial. BMC Pregnancy Childbirth. 2012;12:63. doi:10.1186/1471-2393-12-63
13. McCauley M, Stewart C, Kebede B. A survey of healthcare providers' knowledge and attitudes regarding pain relief in labor for women in Ethiopia. BMC Pregnancy Childbirth. 2017;17(1):56. doi:10.1186/s12884-017-1237-4

14. ACOG Practice Bulletin No. 36: Obstetric Analgesia and Anesthesia. Obstet Gynecol. 2002;100(1):177-191.

15. Vincent RD Jr, Chestnut DH. Epidural analgesia during labor. Am Fam Physician. 1998;58(8):1785-1792.

16. National Institute for Health and Care Excellence. Intrapartum care for healthy women and babies. Clinical guideline 2014. https://www.nice.org.uk/guidance/cg190. Accessed 22nd June, 2017.

17. Knox A, Rouleau G, Semenic S, Khongkham M, Ciofani L. Barriers and facilitators to birth without epidural in a tertiary obstetric referral center: Perspectives of health care professionals and patients. Birth. 2018;45(3):295-302. doi:10.1111/birt.12327

18. Bajwa SK, Bajwa SJ, Singh K, Singh A. Painless labour: how far have we travelled? Sri Lanka J Obstet Gynaecol. 2010;32(4):93-98. doi:10.4038/sljog.v32i4.3992

19. ACOG Committee Opinion \#295: pain relief during labor. Obstet Gynecol. 2004;104(1):213.

20. Vandendriesen NM, Lim W, Paech MJ, Michael C. Obstetricians' knowledge and attitudes toward epidural analgesia in labour. Anaesth Intensive Care. 1998;26(5):563567.

21. Lim G, Farrell LM, Facco FL, Gold MS, Wasan AD. Labor Analgesia as a Predictor for Reduced Postpartum Depression Scores: A Retrospective Observational Study. Anesth Analg. 2018;126(5):1598-1605. doi:10.1213/ ane.0000000000002720

22. Vandendriesen NM, Lim W, Paech MJ. Labour ward midwifery staff epidural knowledge and practice. Anaesth Intensive Care. 1998;26(4):411-419.

23. Freeman LM, Bloemenkamp KW, Franssen MT, et al. Patient controlled analgesia with remifentanil versus epidural analgesia in labour: randomised multicentre equivalence trial. BMJ. 2015;350:h846. doi:10.1136/bmj.h846

24. Black JD, Cyna AM. Issues of consent for regional analgesia in labour: a survey of obstetric anaesthetists. Anaesth Intensive Care. 2006;34(2):254-260.

25. Engel NM, Van de Velde M, Nijhuis JG, Marcus MA. Labour analgesia effects on foetal heart rate. A mini-review. Open J Obstet Gynecol. 2011;1(3):113-120. doi:10.4236/ ojog.2011.13020

(C) 2018 The Author (s); This is an open-access article distributed under the terms of the Creative Commons Attribution License (http://creativecommons.org/licenses/by/4.0), which permits unrestricted use, distribution, and reproduction in any medium, provided the original work is properly cited. 